Article

\title{
Extraction of Peptidoglycan from L. paracasei subp. Paracasei X12 and Its Preliminary Mechanisms of Inducing Immunogenic Cell Death in HT-29 Cells
}

\author{
Pei-Jun Tian ${ }^{1, \dagger}$, Bao-Long Li ${ }^{2, \dagger}$, Yu-Juan Shan ${ }^{1, *}$, Jin-Na Zhang ${ }^{3}$, Jing-Yu Chen ${ }^{1}$, Min Yu ${ }^{2}$ \\ and Lan-Wei Zhang $1, *$
}

1 School of Food Science and Engineering, Harbin Institute of Technology, No. 73 Huanghe Road, Harbin 150000, China; E-Mails: tianpei0202@gmail.com (P.-J.T.);

hgdchenjingyu@gmail.com (J.-Y.C.)

2 Center of Safety and Evaluation of Drugs, Heilongjiang University of Chinese Medicine,

No. 24 Heping Road, Harbin 150000, China; E-Mails: 1b173@163.com (B.-L.L.); hzyyumin@gmail.com (M.Y.)

3 School of Municipal and Environmental Engineering, Harbin Institute of Technology, No.73 Huanghe Road, Harbin 150000, China; E-Mail: zzjjnn-4@163.com

$\dagger$ These authors contributed equally to this work.

* Authors to whom correspondence should be addressed;

E-Mails: shanyujuan@hit.edu.cn (Y.-J.S.); lanweizhang@yahoo.com.cn (L.-W.Z.);

Tel.: +86-451-8628-2021 (Y.-J.S. \& L.-W.Z.); Fax: +86-451-8628-2906 (Y.-J.S. \& L.-W.Z.).

Academic Editor: Maurizio Battino

Received: 28 June 2015 / Accepted: 18 August 2015 / Published: 24 August 2015

\begin{abstract}
L. paracasei subp. paracasei X12 was previously isolated from a Chinese traditional fermented cheese with anticancer activities and probiotic potential. Herein, the integral peptidoglycan (X12-PG) was extracted by a modified trichloroacetic acid (TCA) method. X12-PG contained the four representative amino acids Asp, Glu, Ala and Lys, and displayed the similar lysozyme sensitivity, UV-visible scanning spectrum and molecular weight as the peptidoglycan standard. X12-PG could induce the production of apoptotic bodies observed by transmission electron microscopy (TEM). X12-PG could significantly induced the translocation of calreticulin (CRT) and the release of high mobility group box 1 protein (HMGB1), the two notable hallmarks of immunogenic cell death (ICD), with the endoplastic reticulum (ER) damaged and subsequently intracellular $\left[\mathrm{Ca}^{2+}\right]$ elevated.
\end{abstract}


Our findings implied that X12-PG could induce the ICD of HT-29 cells through targeting at the ER. The present results may enlighten the prospect of probiotics in the prevention of colon cancer.

Keywords: peptidoglycan; immunogenic cell death; calreticulin; calcium

\section{Introduction}

Colon cancer is one of leading causes of cancer death [1]. Several risk factors including westernized diet, obesity and physical inactivity have been demonstrated to closely relate to colon cancer [2]. The microenvironment within colorectal neoplastic lesions significantly differs from the normal, where varieties of bacterial species are enriched such as Bacteroides fragilis, Bacteroides vulgatus, Bifidobacterium longum, Clostridium butyricum, Mitsuokella multiacida, Escherichia coli, Enterococcus faecalis and Streptococcus bovis [3]. The shift from normal microbiota to dysbiosis would increase the pathogenic potential of organisms, ultimately to chronic inflammation and high risks of colon cancer. In 1951, McCoy and Mason reported that a carcinoma of the cecum is associated with enterococcal endocarditis [4]. Since then more and more studies reported that chronic intestinal inflammation is a well-established risk factor for colon cancer [5]. Although the detailed interactions between colonic microflora and colon cancer are not fully understood, a certain composition of gut microbiota may be efficient in the prevention of chronic inflammation and carcinogenesis $[6,7]$.

In recent years, probiotics and prebiotics are increasingly consumed in daily diet. Probiotic has been defined as live microorganisms that confer a number of health benefits on the host, including enhancing immunity, modifying gut associated lymphoid tissue, relieving hypersensitivity, alleviating inflammatory bowel disease, as well as anti-infection and anticancer effects [8], etc. Especially probiotic lactobacilli and bifidobacteria are reported to have the capacity of influencing the intestinal microbiota or alleviating certain pathologies involving the gut immune system $[9,10]$. Other studies suggest that probiotics are protective against colorectal cancer. For example, oral administration of Lactobacillus acidophilus-formulated yogurt in mice brought on a significant decrease of colon tumor incidence, tumor multiplicity and tumor size [11]. In addition, a large-scale clinical study on 398 colon cancer patients free from tumor after surgery demonstrated that intake of Lactobacillus casei could decline the recurrence rate of colon cancer [12]. Another clinical study showed that oral intake of probiotics could improve the integrity of gut mucosal barrier and the balance of gut microbiota, which contributes to decreasing the infection rate [13]. Moreover, many studies have confirmed that not only the whole probiotics, but also the components and metabolic compositions, distinctively influenced the inhibitory effects on colon cancer [14]. For instance, cell walls of bifidobacterial can stimulate the lymphocytes proliferation and cytokine production [15]. Currently, surgery is still the main therapy for colon cancer but risked a high recurrence rate [16]. The adjuvant therapy such as chemotherapy and radiation therapy inevitably will bring some side effects like myelosuppression and thrombocytopenia [17,18]. Given these, there may be a considerable potential of the application of probiotics in the treatment of colon cancer [19].

In human bodies, the innate immune system is the first defense against the outside attack. This system is built around the germline-encoded pattern recognition receptors, which can recognize certain 
microbial-associated molecular, and finally trigger the host response. Peptidoglycan, the conserved structural component in the bacterial cell wall, is a good innate immune target [20]. Almost all of the bacteria cell walls contain peptidoglycan; the content of peptidoglycan in Gram-positive bacteria ranges from $30 \%$ to $95 \%$, indicating its possible physiological functions. As an activator of the human immune system, peptidoglycan can induce intestinal epithelial cells to produce cytokines such as pro-inflammatory cytokines IL-12p35, IL-8 and tumor necrosis factor- $\alpha$ (TNF- $\alpha$ ) in a time-dependent manner [21]. L. paracasei subp. paracasei X12 (X12) is derived from a traditional cheese in Xinjiang, China. Our previous results showed that the live bacteria inhibited the proliferation of HT-29 cells. Besides, the cell walls extracted from bacteria can also induce apoptosis in HT-29 cells [22]. All these findings implicate the potential of peptidoglycan in the prevention and therapy for colon cancer.

Recent studies suggest that apoptotic cell death could be immunogenic under certain circumstances, which means the tumor cells in early stages of apoptosis would be immunologically recognized, attacked by immunocytes and eventually result in immunogenic apoptosis [23]. The cells undergoing immunogenic death are able to release or translocate specific signals such as calreticulin (CRT), heat shock proteins (HSPs), high mobility group box 1 protein (HMGB1), ATP [24-28], etc. Some of the signals are operated on a series of receptors controlled by dendritic cells which present the tumor antigens to T-lymphocytes, constituting a pathway to activate the therapeutic immune responses [29].

Based on the aforementioned information, we hypothesized that the peptidoglycan extracted from $\mathrm{X} 12$ (X12-PG) may play an important role in its inhibitory effects on colon cancer [22]. Clarifying the key mechanisms and the target of peptidoglycan will provide novel strategies for exploring, exploiting and applying probiotics products in the future.

\section{Results}

\subsection{Extraction and Qualitative Analysis of X12-PG}

Extraction of X12-PG was processed according to the modified trichloroacetic acid (TCA) method. To maintain the physical integrity of the cell wall structure, this isolation procedure did not result in any physical destructive processes. Also this extraction removed virtually all the teichoic acid from the cell wall. The extraction yield of X12-PG is $6.79 \%$, which was calculated by the dry weight of extracts/bacterial sludge ratio. The results of electron microscopic observation are shown in Figure 1, where a cystic structure and extremely neat edges are seen in X12-PG. In sharp contrast, the X12 bacterial cells are more distinct with dark interior regions.

Peptidoglycan is chiefly composed of chains of $N$-acetylglucosamine (GlcNAc) and $N$-acetylmuramic acid (MurNAc) attached to stem peptides. The total carbohydrate content of X12-PG is $199.16 \mathrm{mg} / \mathrm{g}$, the protein content was calculated as $20.31 \mathrm{mg} / \mathrm{g}$. Lysozyme assay is generally used as a qualitative test for peptidoglycan. Because the $\beta$-1,4-linked GlcNAc and MurNAc structure in X12-PG can be exclusively hydrolyzed by lysozyme, the absorbance values (A450 nm) sharply declined during the first two incubation hours (Figure 2A), whereas no obvious and fast dropping was observed in X12 solution during the whole process. The results suggested that X12-PG possessed the characteristics of peptidoglycan. 


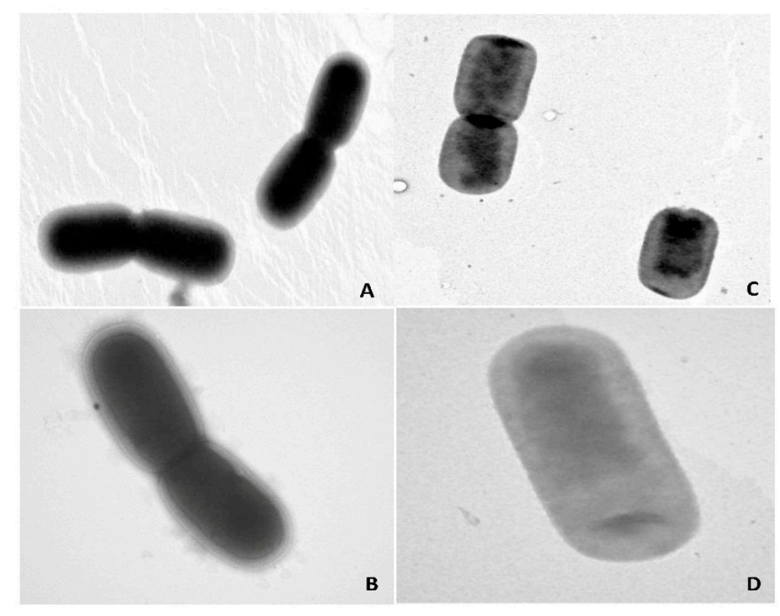

Figure 1. Structural features of the integral peptidoglycan isolated from L. paracasei subp. paracasei X12 (X12-PG) and the L. paracasei subp. paracasei X12 bacteria $(\mathrm{X} 12)$ observed by transmission electron microscope (TEM). (A,B) The structure of X12 $(\times 20,000$, $\times 40,000)$; (C,D) The cylindrical structure of internal X12-PG $(\times 20,000, \times 40,000)$.
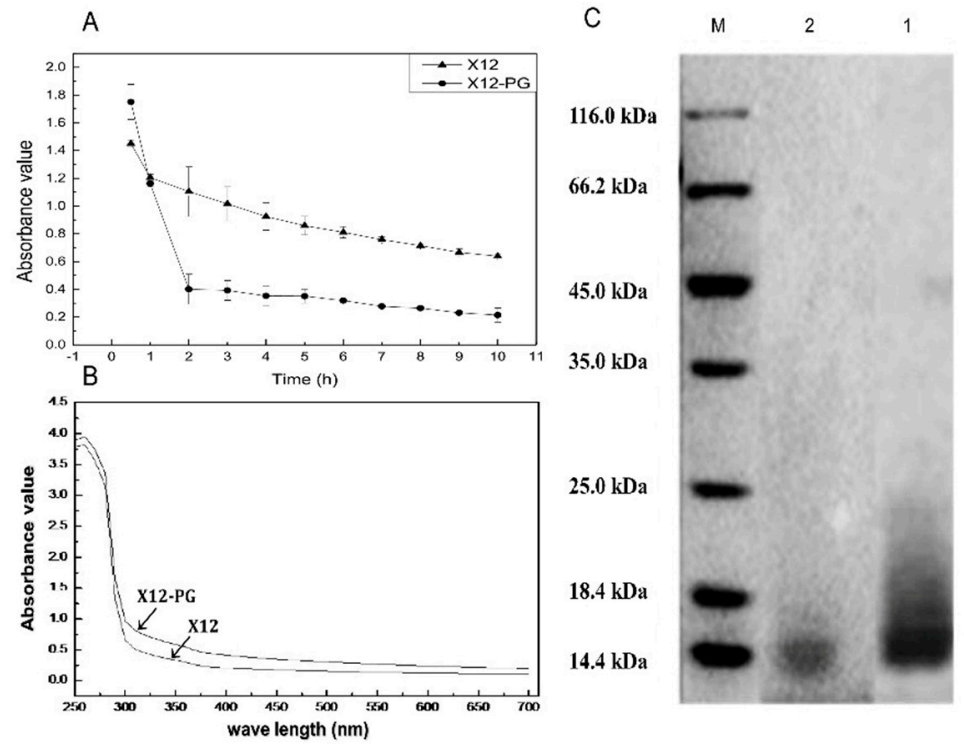

Figure 2. Quantitative and qualitative analysis of X12-PG. (A) The degradation models of X12-PG and X12 when exposed to lysozyme. A450 nm of X12-PG declined faster than that of X12; (B) The UV-visible scanning spectrum of X12-PG and peptidoglycan standard. The standards and samples were scanned between 190 and $700 \mathrm{~nm}$ in a UV/VIS spectrophotometer; and $(\mathbf{C})$ The molecular weight $(\mathrm{kDa})$ of X12-PG quantified by SDS-PAGE. The gels were stained with Coomassie Brilliant Blue. The molecular weight was $14 \mathrm{kDa}$, corresponding to the peptidoglycan standard. Each graph represents the average of more than three replications.

Table 1 shows the result of amino acid analysis. Contents of Asp $(0.361 \mathrm{mmol} / \mathrm{g}), \mathrm{Glu}(0.381 \mathrm{mmol} / \mathrm{g})$, Ala $(0.649 \mathrm{mmol} / \mathrm{g})$, Lys $(0.268 \mathrm{mmol} / \mathrm{g})$ were the highest when compared with other amino acids. Moreover, these four amino acids are specifically found in lactobacillus peptidoglycan [30], which in turn revealed that the extracts were essentially peptidoglycan. Evidence to support this belief 
was supplied by UV-visible scanning spectrum $(190-700 \mathrm{~nm})$ and molecular weight of both peptidoglycan standard and X12-PG. They delivered nearly coincident curves with the same absorption peaks and shapes (Figure 2B). The molecular weight of X12-PG was around $14.4 \mathrm{kDa}$, the same as the standard sample (Figure 2C). Therefore, we confirmed that the extracted X12-PG was peptidoglycan.

Table 1. The composition and contents of amino acids.

\begin{tabular}{cccc}
\hline & Amino Acids & Concentration $(\boldsymbol{\mu g} / \mathbf{m L})$ & Contents $(\mathbf{m m o l} / \mathbf{g})$ \\
\hline 1 & Glu & 56.44 & 0.381 \\
2 & Arg & 6.80 & 0.039 \\
3 & Thr & 12.74 & 0.106 \\
4 & Tyr & 11.11 & 0.060 \\
5 & Val & 8.52 & 0.072 \\
6 & Met & 11.35 & 0.076 \\
7 & Cys & 7.27 & 0.060 \\
8 & Ile & 8.19 & 0.062 \\
9 & Phe & 9.55 & 0.057 \\
10 & Asp & 48.54 & 0.361 \\
11 & Ser & 9.75 & 0.093 \\
12 & Gly & 7.88 & 0.105 \\
13 & His & 12.26 & 0.078 \\
14 & Ala & 57.83 & 0.649 \\
15 & Pro & 1.02 & 0.009 \\
16 & Leu & 16.85 & 0.128 \\
17 & Lys & 39.56 & 0.268 \\
\hline
\end{tabular}

\subsection{X12-PG Induced Apoptosis in HT-29 Cells}

Morphological studies of X12-PG-treated and untreated HT-29 cells were carried out by TEM. In untreated cells, a large number of villi-like projections on cell surface were distributed uniformly. In addition, nuclear chromatin and intact organelles such as endoplasmic reticulum, mitochondria and ribosomes, were clearly observed (Figure 3A). In X12-PG-treated cells, however, villous structures were gradually diminished, meanwhile accompanied by mitochondria degradation, increased cytoplasmic vacuoles and formation of apoptotic bodies (Figure 3B,C, arrows showed apoptotic body). This alteration was enhanced when the treatment concentration increased, especially at $1600 \mu \mathrm{g} / \mathrm{mL}$, villous structures almost completely disappeared. Except for mature apoptotic bodies, cell shrinkage and increased nuclear/cytoplasmic ratio were also observed (Figure 3D).

Peptidoglycan is chiefly composed of chains of $N$-acetylglucosamine (GlcNAc) and $N$-acetylmuramic acid (MurNAc) attached to stem peptides. The total carbohydrate content of X12-PG is $199.16 \mathrm{mg} / \mathrm{g}$, the protein content was calculated as $20.31 \mathrm{mg} / \mathrm{g}$. Lysozyme assay is generally used as a qualitative test for peptidoglycan. Because the $\beta$-1,4-linked GlcNAc and MurNAc structure in X12-PG can be exclusively hydrolyzed by lysozyme, the absorbance values (A450 nm) sharply declined during the first two incubation hours (Figure 2A), whereas no obvious and fast dropping was observed in X12 solution during the whole process. The results suggested that X12-PG possessed the characteristics of peptidoglycan. 


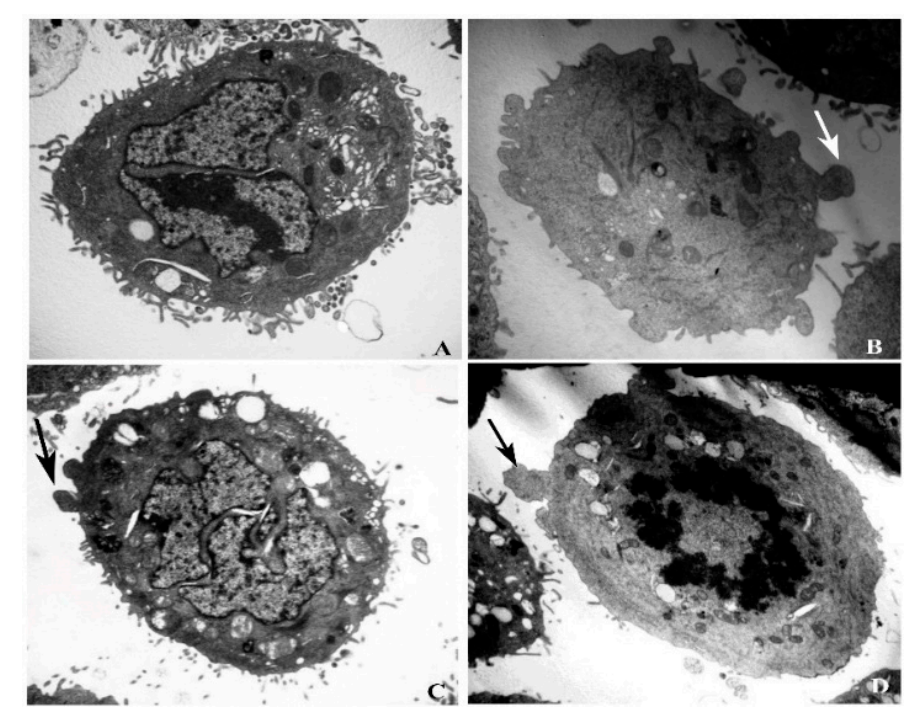

Figure 3. Apoptosis of HT-29 cells after treatment of X12-PG. (A-D) were respectively treated with $0,400,800,1600 \mu \mathrm{g} / \mathrm{mL}$ X12-PG for $48 \mathrm{~h}$. HT-29 cells were observed by TEM $(\times 6000)$. The arrows indicate the apoptotic bodies.

The effects of X12-PG on cell proliferation were measured by MTT assay. As shown in Table 2, the inhibition rate of HT-29 cells became more significant when treatment concentration increased. We used oxaliplatin (OXP) as a standard ICD inducer that is widely approved [31], and which result in an inhibition rate of $74.21 \%$. In our previous article we reported the minor toxic activity of X12-PG in noncancerous cells when compared with that in HT-29 cells; they released selective growth inhibitors, which specifically targeted cancer cells [22], so X12-PG can be investigated in a safe anticancer therapy agent. After treatment with $1600 \mu \mathrm{g} / \mathrm{mL}$ X12-PG, the apoptotic cells (\%) reached $61.03 \%$.

Table 2. Cell viability measured by MTT assay.

\begin{tabular}{cc}
\hline Treatment & Apoptotic Cells (\%) \\
\hline OXP $(15 \mu \mathrm{mol} / \mathrm{L})$ & $74.21 \pm 0.38$ \\
$\mathrm{X} 12-\mathrm{PG}(400 \mu \mathrm{g} / \mathrm{mL})$ & $50.42 \pm 0.46$ \\
$\mathrm{X} 12-\mathrm{PG}(800 \mu \mathrm{g} / \mathrm{mL})$ & $55.65 \pm 0.40$ \\
$\mathrm{X} 12-\mathrm{PG}(1600 \mu \mathrm{g} / \mathrm{mL})$ & $61.03 \pm 0.35$ \\
\hline
\end{tabular}

\subsection{Damaged to Endoplasmic Reticulum Induced by X12-PG in HT-29 Cells}

The endoplasmic reticulum (ER) is an important organelle that fulfills a multiple of cellular functions. In most cases, cytoplasmic ER morphologically shapes like thin lines (Figure 4A). Compared with the control, when treated with $400 \mu \mathrm{g} / \mathrm{mL}$ X12-PG, ER became darker and swelled. Moreover, hair-like projections on the membrane were gradually distorted and reduced (Figure 4B). X12-PG of $800 \mu \mathrm{g} / \mathrm{mL}$ led to the formation of vacuoles and clearer ER dilation (Figure 4C). At the dose of $1600 \mu \mathrm{g} / \mathrm{mL}$, the ER were further swelled in larger quantities (Figure 4D). These results suggest that X12-PG was able to alter structural features of ER and eventually damage its physiological function. 


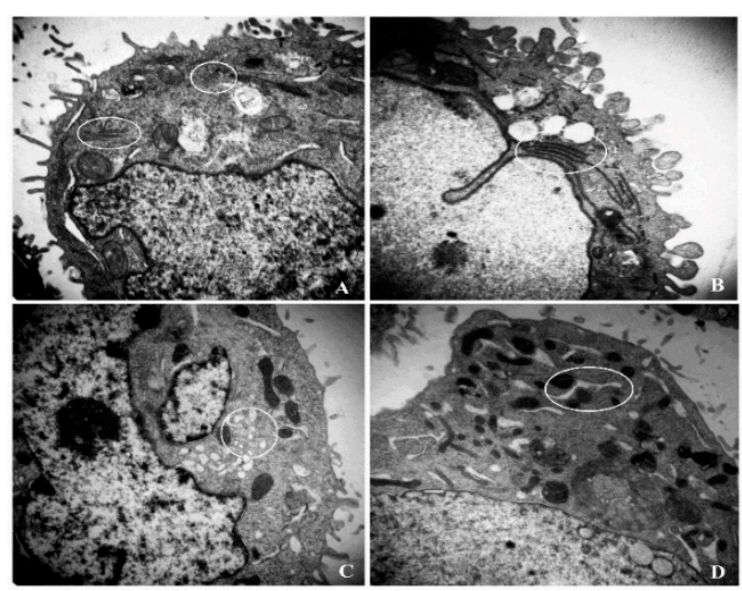

Figure 4. Structural damages of endoplasmic reticulum (ER) after treatment of X12-PG. (A-D) were respectively treated with $0,400,800,1600 \mu \mathrm{g} / \mathrm{mL}$ X12-PG for $48 \mathrm{~h}$. Cells were observed by TEM $(\times 20,000)$. The encircled regions show the location of ER.

\subsection{X12-PG Induced the Translocation of Calreticulin (CRT) and Release of HMGB1}

CRT is a high-affinity $\mathrm{Ca}^{2+}$-binding protein. The majority of cellular CRT is located in the ER, where it participates in modulating intracellular $\mathrm{Ca}^{2+}$ homeostasis and $\mathrm{Ca}^{2+}$ signaling. After stimulation $(48 \mathrm{~h})$ for X12-PG, CRT was exposed on the cell surface, as determined by immunofluorescence staining (Figure 5) or flow cytometry analysis (Figure 6). Sparse but clear fluorescence (Anti-CRT-FITC) on the membrane emerged when treated with $400 \mu \mathrm{g} / \mathrm{mL}$ X12-PG. Fluorescence intensity was enhanced when treated with a range of increasing concentrations, indicating more and more CRT translocated to the cell membrane (Figure 5). In identical conditions, the content of CRT was quantified by flow cytometry based on mean fluorescence intensity (MFI): CRT exposure significantly $(p<0.01)$ increased when treated with $1600 \mu \mathrm{g} / \mathrm{mL}$ X12-PG (Figure 6).

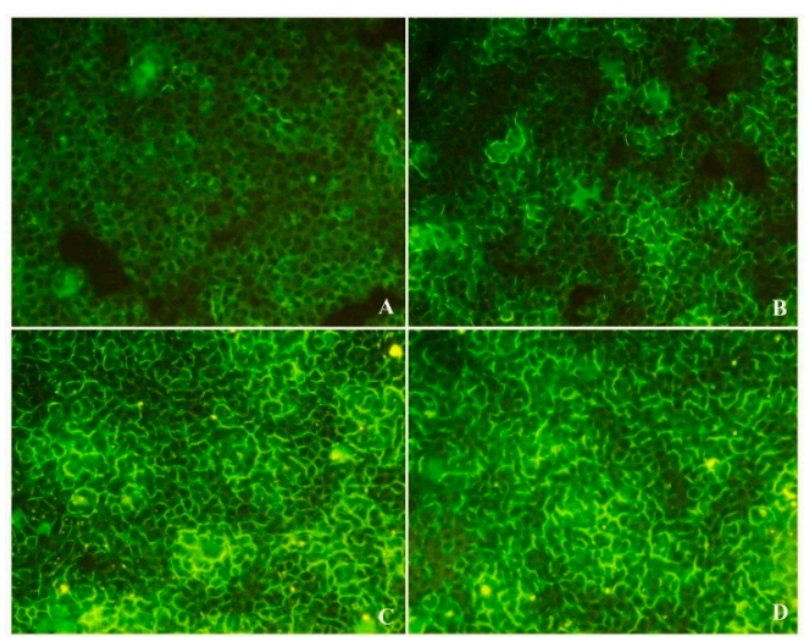

Figure 5. Calreticulin (CRT) exposure detected by immunofluoroscence assay after treatment of X12-PG. (A-D) were respectively treated with $0,400,800,1600 \mu \mathrm{g} / \mathrm{mL}$ $\mathrm{X} 12-\mathrm{PG}$ for $48 \mathrm{~h}$, then incubated with primary antibody (Anti-Calreticulin, diluted 1:200 in blocking buffer) and detected with the FITC-labeled secondary antibody. Fluorescence intensity was visualized by immunofluorescence microscopy $(\times 200)$. 
Dying cells also released the cell death-associated nuclear HMGB1 protein into the extracellular milieu in a dose dependent manner (Table 3). When stimulated with 800 and $1600 \mu \mathrm{g} / \mathrm{mL}$ X12-PG, the concentration of HMGB1 in the supernatants were increased by $109 \%(15.86 \pm 0.32 \mathrm{ng} / \mathrm{mL}, * p<0.05)$ and $185 \%(21.58 \pm 0.36 \mathrm{ng} / \mathrm{mL}, * * p<0.01)$ respectively compared with the control $(7.56 \pm 8.5 \mathrm{ng} / \mathrm{mL})$. Altogether, these results revealed the ability of X12-PG in eliciting CRT translocation and HMGB1 secretion, which are necessary for signaling immunogenicity and ultimately leading to ICD.

Table 3. ELISA detection of HMGB1 release in the supernatants of HT-29 cells.

\begin{tabular}{cc}
\hline X12-PG Treatment $(\boldsymbol{\mu g} / \mathbf{m L})$ & HMGB1 Concentration $(\mathbf{n g} / \mathbf{m L})$ \\
\hline 0 & $7.56 \pm 0.35$ \\
400 & $9.52 \pm 0.35$ \\
800 & $15.86 \pm 0.32 *$ \\
1600 & $21.58 \pm 0.36^{* *}$ \\
\hline
\end{tabular}
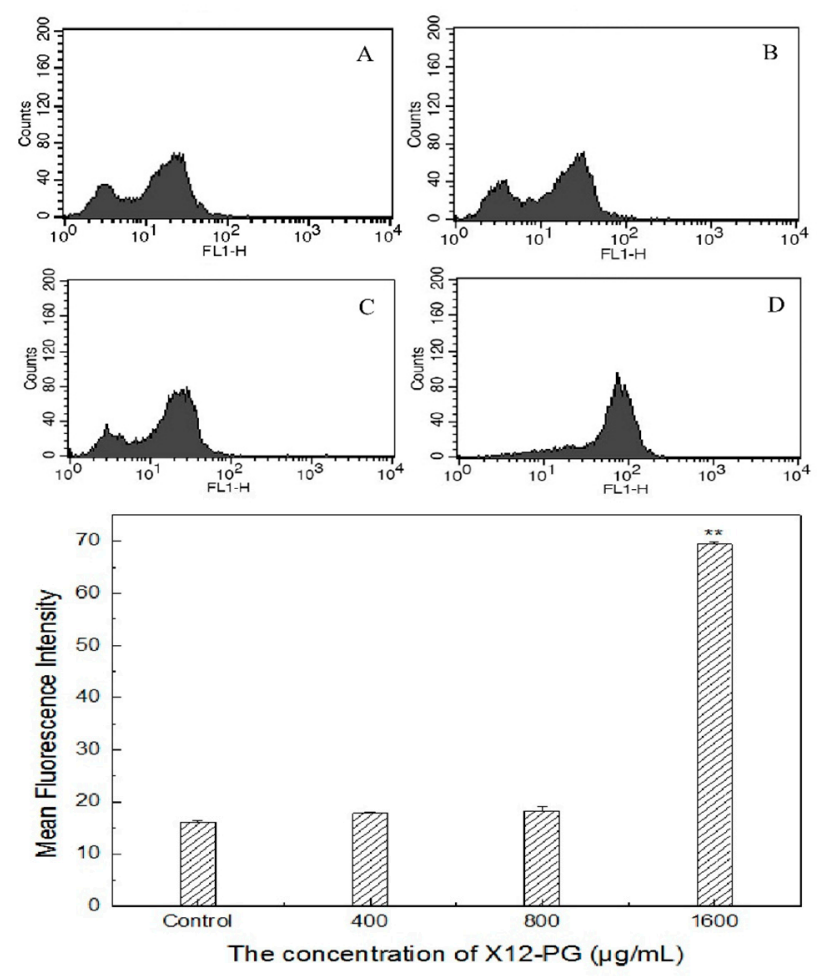

Figure 6. CRT exposure detected by flow cytometry after treatment of X12-PG. Prior to analysis, cells were respectively treated with $0,400,800,1600 \mu \mathrm{g} / \mathrm{mL}(\mathbf{A}-\mathbf{D})$ X12-PG for $48 \mathrm{~h}$, then harvested and labeled with FITC. The concentration of CRT on cell membrane was expressed as mean fluorescence intensity (MFI) which has excluded background (Isotype-matched IgG was used as a control: Data not shown). (Error bars are mean $\pm \mathrm{SD}$, $* * p<0.01$ versus control)

\subsection{X12-PG Promoted the Release of $\mathrm{Ca}^{2+}$ from the ER into the Cytoplasm}

We next examined the correlation among cytosolic free $\mathrm{Ca}^{2+}$, CRT exposure and ER dysfunction. Normally, $\mathrm{Ca}^{2+}$ is stored in the ER where physiological activities are regulated through the uptake or release of $\mathrm{Ca}^{2+}$. Intracellular $\mathrm{Ca}^{2+}$ concentration $\left(\left[\mathrm{Ca}^{2+}\right]\right)$ was measured with the fluorescent probe Fluo-3/AM 
by flow cytometry. The MFI of $\left[\mathrm{Ca}^{2+}\right]$ in the cytoplasm were increased by $18 \%(437.5 \pm 6.5), 35 \%$ $(499.5 \pm 4.5)$ and $85 \%(681.5 \pm 3.5, p<0.01)$ respectively, compared with the control group $(369.5 \pm 8.5)$ after exposure to $400,800,1600 \mu \mathrm{g} / \mathrm{mL}$ X12-PG for $48 \mathrm{~h}$ (Figure 7). Before this, we had observed $\mathrm{X} 12-\mathrm{PG}$-induced structural damage of ER, as well as CRT translocation. Although the mechanisms accounting for CRT exposure remain largely elusive, based on the data summarized in this work, we assumed that ER $\left[\mathrm{Ca}^{2+}\right]$ homeostasis plays a major role in the regulation of CRT exposure as it is induced by X12-PG.
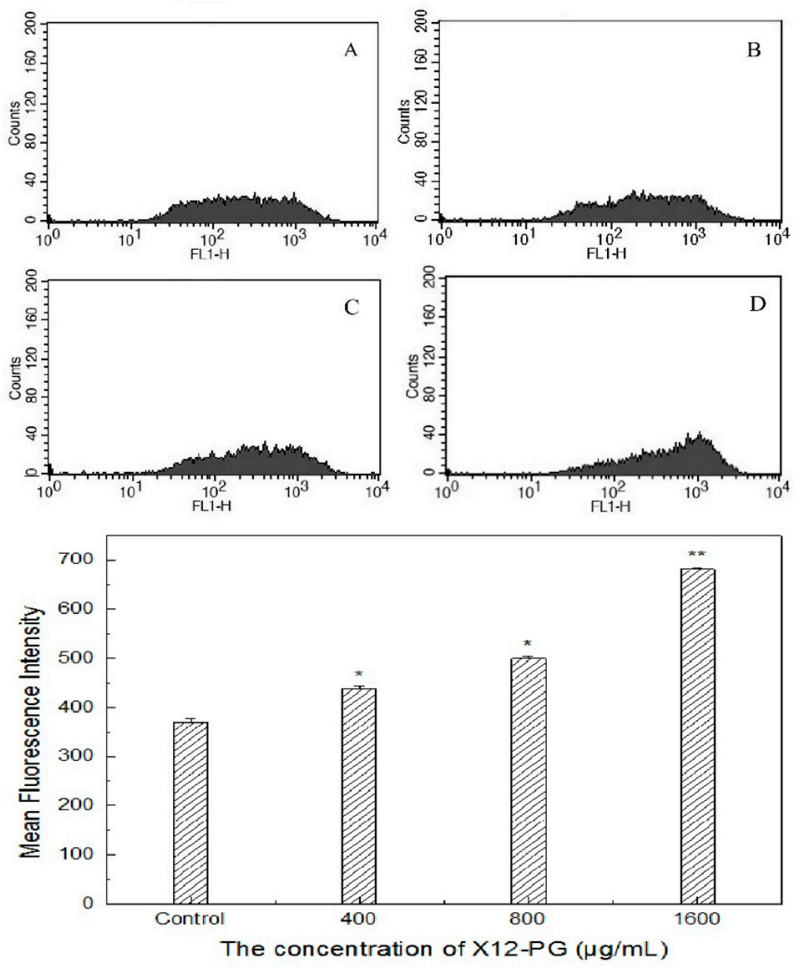

Figure 7. Intracellular $\mathrm{Ca}^{2+}$ concentration $\left(\left[\mathrm{Ca}^{2+}\right]\right)$ after treatment of X12-PG. (A-D) were respectively treated with $0,400,800,1600 \mu \mathrm{g} / \mathrm{mL} \mathrm{X12-PG} \mathrm{for} 48 \mathrm{~h}$. Cytosolic $\left[\mathrm{Ca}^{2+}\right.$ ] was increased in a dose-dependent manner after exposure to X12-PG. HT-29 cells were loaded with Fluo-3/AM and analyzed by flow cytometry. Fluo-3/AM was excited at the $488 \mathrm{~nm}$ line of an argon laser and the fluorescence intensity was measured at an emission wavelength $530 \mathrm{~nm}$. $\left[\mathrm{Ca}^{2+}\right]$ was expressed as mean fluorescence intensity (MFI). (Error bars are mean $\pm \mathrm{SD}, * p<0.05$ versus control, $* * p<0.01$ versus control).

\section{Discussion}

In the present study, we extracted peptidoglycan (X12-PG) from the L.paracasei subp. paracasei X12 which previously showed potential anti-colon tumor activities. The current results revealed that X12-PG could induce immunogenic apoptosis in HT-29 cells, characteristically displayed by CRT translocation, HMGB1 secretion, the increased intracellular $\left[\mathrm{Ca}^{2+}\right]$ levels, as well as some classical evidence, for instance, apoptotic bodies and ER damage.

For the compact structure of bacterial cell wall, it is difficult to find a proper isolation method that can remove all the cell contents but concurrently retain structural integrity of the cell wall. The earliest 
method of integral peptidoglycan extraction is documented by Sekine et al. [32]. According to this method, Yue and Hu successfully extracted the integral peptidoglycan from Bifidobacterium sp. [33], however, the extraction step is complicated, with a long extraction period but low extraction yield. Herein, we slightly modified the TCA method in order to shorten the extraction period and improve the yield. The yield reached $6.79 \%$ in a four-day extraction. Quantitative and qualitative determinations such as lysozyme sensitivity [34], molecular weight and amino acid analysis further confirmed that X12-PG was essentially a peptidoglycan [35].

It is generally assumed that eradicating all cancer cells-including cancer stem cells and early micrometastases-by direct cytostatic or cytotoxic effects, contributes to the complete and permanent cure of cancer. Based on this simplistic belief, induction of apoptosis by conventional chemotherapy or radiotherapy is thought to be non-inflammatory and non-immunogenic. Accumulated evidence has demonstrated that long-term clinical success of chemotherapeutics, such as anthracyclines- or oxaliplatin-induced apoptotic cell death, can be immunogenic and hence elicit active immune responses against dying tumor cells [36]; this mechanism is commonly known as immunogenic cell death (ICD).

Nonetheless, chemotherapy is still the most common and effective treatment for various cancers, it should be noted that the side effect of cytotoxic and new oncological danger would impact the quality of life from these treatments [37]. As already known, a large number of probiotic lactobacillus exerts potential anticancer effects by inducing apoptosis or promoting the production of immune factors. While the underlying mechanisms require further exploration, not only the whole live cells, but also the heat-killed cells, cell walls and cytoplasm exhibited the abilities of suppressing the growth of colon cancer cells [38-40]. Interestingly, the X12-PG extracted from L. paracasei subp. paracasei X12 could induce cell apoptosis and CRT exposure in HT-29 cells. Driven by these considerations, we established the primary mechanism of X12-PG-induced ICD in HT-29 cells and the anticancer potential of probiotics.

CRT exposure on the membrane serves as an engulfment signal in pre-apoptotic cells for specific interaction with dendritic cells (DCs), which could engulf, process, and present antigen from dying tumor cells to T-lymphocytes. The activated immune defensing system will eventually kill the tumor cells. Obeid et al. reported that CRT was exposed on the surface of cells undergoing ICD, but was lacking in those cells with non-immunogenic cell death [24]. Conversely, anti-neoplastic agents that fail to induce CRT exposure are intrinsically incapable of provoking ICD [41]. All these studies identify CRT as a major checkpoint of ICD. CRT is an abundant chaperone that is normally secluded in the ER lumen; it is able to translocate to the plasma membrane under a series of ER stress responses through a complex pathway, including paracrine signals and transduction cascade activations. CRT is also a high capacity $\mathrm{Ca}^{2+}$-binding protein of intracellular $\mathrm{Ca}^{2+}$ stores and CRT translocation breaks ER-regulation of $\mathrm{Ca}^{2+}$ homeostasis [42]. Moreover, this disturbance may synergistically aggravate CRT translocation. As described in a previous study, after cells were transfected with a Reticulon-1C (an evolutionary conserved protein to decrease the $\left[\mathrm{Ca}^{2+}\right]$ in the ER) overexpression plasmid, the ER could no longer mediate CRT exposure in response to anthracyclin treatment [43]. In addition, cells undergoing ICD release the nuclear protein HMGB1 as their membranes become permeabilized during secondary necrosis [29]. HMGB1 can interact with several receptors expressed on the surface of DCs including the toll-like receptor 4 (TLR4) [26,28]. Combing the previous studies and our experimental results, we speculate that the ER structure damages induced by X12-PG treatment, directly results in the reduction of endoplasmic reticulum $\left[\mathrm{Ca}^{2+}\right]$ levels and elevation of intracellular $\left[\mathrm{Ca}^{2+}\right]$. Subsequently, 
$\mathrm{Ca}^{2+}$ served as a translocation signal and triggered CRT exposure onto the cell surface (Figure 8). To our knowledge, no detailed molecular mechanisms of how CRT translocated to the cell membrane has been clearly clarified, and it is a problem that requires further investigation.

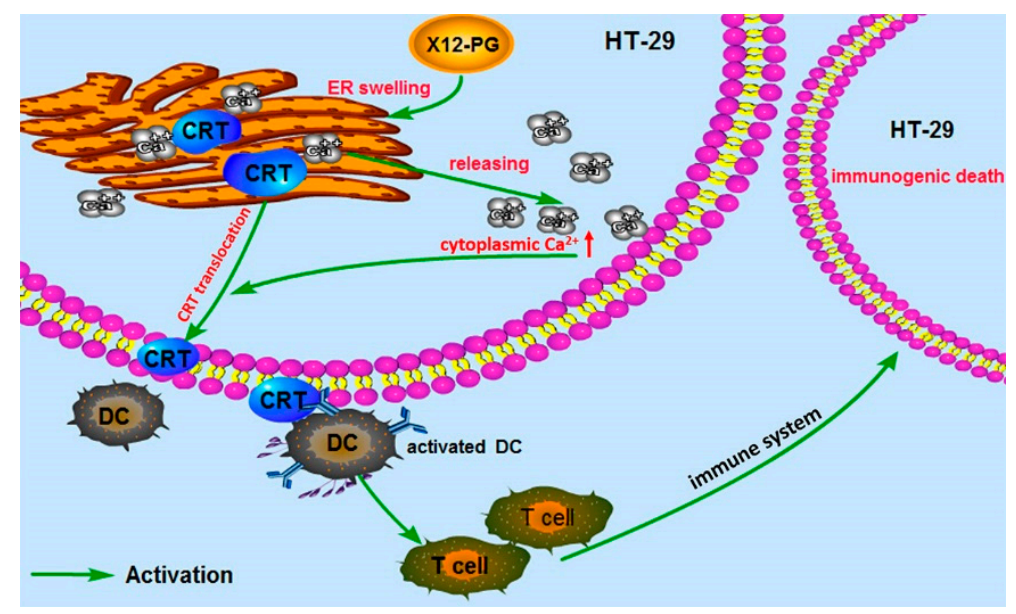

Figure 8. Properties of immunogenic cell death (ICD) induced by X12-PG in HT-29 cells. As a result of endoplasmic reticulum stress (stimulated by X12-PG), cancer cells expose CRT on their plasma membrane at a pre-apoptotic stage. This facilitates the recruitment of dendritic cells (DCs) into the tumor bed, the engulfment of tumor antigens by DCs (stimulated by CRT), and optimal antigen presentation to T cells (stimulated by HMGB1). CRT served as an "eat-me" signal, and CRT exposure may be regulated by cytosolic $\left[\mathrm{Ca}^{2+}\right]$.

\section{Experimental Section}

\subsection{Reagents}

Peptidoglycan standard, Anti-Calreticulin, MTT, were obtained from Sigma Co. (St. Louis, MO, USA). Bradford Protein kit, Fulo-3/AM and Fluorescein Isothiocyanate (FITC)-labeled secondary antibody (goat anti-rabbit) were from Bi YunTian biotechnology Co., Ltd. (Shanghai, China). Coomassie brilliant blue G250 and DMSO were purchased from Lianxing Biotechnology Co., Ltd. (Beijing, China). Other reagents were all analytical grade and supplied by Sinopharm Chemical Reagent Co., Ltd. (Beijing, China).

\subsection{Cell Culture}

HT-29 cells (human colon adenocarcinoma cell line), provided by the Cancer Institute of the Chinese Academy of Medical Science (Beijing, China), were cultured in RPMI-1640 medium supplemented with $10 \%$ fetal-bovine serum (FBS), $1 \%$ L-glutamine, penicillin (100 units $/ \mathrm{mL})$ and streptomycin $(100 \mu \mathrm{g} / \mathrm{mL})$. Cells were maintained at $37{ }^{\circ} \mathrm{C}$ in a humidified atmosphere with $5 \% \mathrm{CO}_{2}$.

\subsection{Isolation and Purification of X12-PG}

L. paracasei subp. paracasei X12 strain was separated from a traditional fermented cheese in Xinjiang province, China. The live bacteria had been previously demonstrated to exert anti-proliferative activity 
and highly adhering capability on HT-29 cells [22]. L. paracasei subp. paracasei X12 was cultured in de Man, Rogosa, Sharpe (MRS) (Difco, Detroit, MI, USA) broth with $0.05 \%$ L-cysteine at $37{ }^{\circ} \mathrm{C}$ under anaerobic conditions. The strain was identified by $16 \mathrm{~S}$ rRNA gene sequences and sub-cultured twice at $37{ }^{\circ} \mathrm{C}$ for $18 \mathrm{~h}$ before use.

The extraction of X12-PG is based on the TCA method as described by Sekine et al. [32]. Briefly, bacterial sludge was washed in $0.9 \%$ saline solution $(w / v=1: 10)$ until it turned white. The clean sludge was dissolved in 10\% TCA $(w / v=1: 10)$, incubated in a boiling bath for $60 \mathrm{~min}$, and then centrifuged at $20,000 \times g$ for $20 \mathrm{~min}$. Collecting the sediment and treated with a special solvent (Acetic acid-sodium acetate buffer (using $0.5 \mathrm{M}$ acetic acid and $0.2 \mathrm{M}$ sodium acetate, $\mathrm{pH} 4.5$ ) chloroform, methanol mix with the ratio of 4:5:10 $(v / v / v), \mathrm{pH} 4.6)$ overnight. After centrifugation $(1000 \times \mathrm{g}$ for $10 \mathrm{~min})$, the insoluble residue was incubated in Tris-HCL $\left(0.1 \mathrm{M}, \mathrm{pH}\right.$ 7.5) containing $2000 \mathrm{U}$ trypsin at $37{ }^{\circ} \mathrm{C}$ in a shaking bath $(140 \mathrm{rpm}$ ) for $12 \mathrm{~h}$. Finally, the mixture was centrifuged at $20,000 \times \mathrm{g}$ for $20 \mathrm{~min}$. The sediment was harvested and washed in sterile water 3-4 times, then lyophilized and stored in an airtight container at $-20{ }^{\circ} \mathrm{C}$ for further analysis.

\subsection{Analytical Methods of X12-PG}

For determination of the $\beta-1,4$-linked MurNAc and GlcNAc, X12-PG was treated with lysozyme $\left(200 \mu \mathrm{g} / \mathrm{mL}\right.$, dissolved in $1 \mathrm{mg} / \mathrm{mL}$ PBS, pH 6.2) at $37^{\circ} \mathrm{C}$ in a shaking bath (140 rpm). X12 was treated identically for comparison. Collecting the reactant every hour, measured its UV absorbance at $450 \mathrm{~nm}$ in a UV/VIS spectrophotometer (METASH UV-5100; Metash: Shanghai, China) during the reaction [34].

The molecular weight of X12-PG was determined by SDS-PAGE analysis. Electrophoresis was carried out in $30 \%$ polyacrylamide gels. The gels were then stained with Coomassie Brilliant Blue G250 and the molecular weight was determined by comparing with the band location of peptidoglycan standard.

For quantitative amino acid analyses, X12-PG samples were hydrolyzed by $6 \mathrm{M} \mathrm{HCl}(v / v=1: 9)$ in a nitrogen atmosphere at $110{ }^{\circ} \mathrm{C}$ for $22 \mathrm{~h}$. The solution was filtered through a $0.45 \mu \mathrm{m}$ membrane filter and quantitative analyses were performed in an amino acid analyzer (Hitachi L-8800; Hitachi: Ibaraki, Japan).

Total carbohydrate content was measured by Phenol-sulfuric acid method. The standard procedure of this method was documented previously [44]. The standard curve was mapped based on the regression equation with a coefficient $\geq 0.999\left(Y=0.00902 X+0.00837, R^{2}=0.9993\right)$. The protein content in X12-PG was measured using a Bradford Protein kit according to the manufacturer's instructions. $\left(Y=1.77705 X+0.02152, R^{2}=0.9992\right)$.

\subsection{Transmission Electron Microscope (TEM)}

The HT-29 cells were seeded in a 6 -well plate $\left(1 \times 10^{6}\right.$ cells $\left./ \mathrm{mL}\right)$ and treated with $0,400,800$, $1600 \mu \mathrm{g} / \mathrm{mL}$ X12-PG for $48 \mathrm{~h}$. The cell pellets were harvested and re-suspended in melted agar medium (2.5\%). The cooled solidified medium was cut into small blocks $(5 \times 2 \times 1 \mathrm{~mm})$, fixed with $5 \%(v / v)$ glutaraldehyde in PBS (0.1 M, pH 7.3) for $2 \mathrm{~h}$, then in $2 \%(w / v)$ osmic acid with the same buffer for $2 \mathrm{~h}$. The blocks were further processed for dehydration, infiltration in a graded ethanol series as previously described [45]. Ultrathin sections were treated with saturated uranyl acetate for $20 \mathrm{~min}$, counterstained 
with $0.3 \%$ lead citrate for another 20 min, finally examined with a Hitachi H-7650 transmission electron microscope in Harbin Medical University.

\subsection{MTT Assay}

HT-29 cells were plated into 96-well microtiter plates $\left(1 \times 10^{6}\right.$ cells $\left./ \mathrm{mL}\right)$ and treated with $0,400,800$, $1600 \mu \mathrm{g} / \mathrm{mL}$ X12-PG for $48 \mathrm{~h}$. MTT (3-(4,5-dimethylthiazol-2-yl)-2,5-diphenyltetrazolium bromide) stock solution $(5 \mathrm{mg} / \mathrm{mL})$ at $10 \mu \mathrm{L}$ per well was added for an additional $4 \mathrm{~h}$. The supernatant was aspirated and the formazan crystals were solubilized in dimethylsulfoxide, followed by determination of optical densities at 560 and $690 \mathrm{~nm}$ using a microtiter plate reader. The spectrophotometer was calibrated to zero absorbance using culture medium without cells. All experiments were run eight times.

\subsection{Immunofluoroscence Assay}

Immunofluoroscence assay was performed as previously described $[22,46]$. The HT-29 cells were cultured in a 6-well plate $\left(1 \times 10^{6}\right.$ cells $\left./ \mathrm{mL}\right)$, after treated with $0,400,800,1600 \mu \mathrm{g} / \mathrm{mL}$ for $48 \mathrm{~h}$, the cell pellets were fixed with $4 \%$ paraformaldehyde on ice for $20 \mathrm{~min}$ and treated with a blocking buffer ( $1 \%$ bovine serum albumin and $1 \%$ fish gelatin in PBS, pH 7.3$)$ at $37{ }^{\circ} \mathrm{C}$ for $30 \mathrm{~min}$. The cells were incubated with primary antibody (Anti-Calreticulin, diluted 1:200 in blocking buffer) and detected with the FITC-labeled secondary antibody. CRT exposure on cell membranes were visualized by immunofluorescence microscopy (Olympus BX51; Olympus Optical: Tokyo, Japan) and photographed.

\subsection{Flow Cytometry Assay}

For measuring alterations of intracellular $\left[\mathrm{Ca}^{2+}\right]$ after X12-PG treatment, HT-29 cells $\left(1 \times 10^{6}\right.$ cells $\left./ \mathrm{mL}\right)$ were loaded with $\mathrm{Ca}^{2+}$ indicator dye by incubating in a Fluo-3/AM buffer ( $5 \mu \mathrm{M}$ Fluo-3/AM and 25\% $(w / w)$ pluronic was mixed in dry DMSO) for $30 \mathrm{~min}$ at room temperature [47]. The cells were diluted to $1 \times 10^{6}$ cells $/ \mathrm{mL}$ in PBS and incubated for $10 \mathrm{~min}$ at $37^{\circ} \mathrm{C}$ to equilibrate calcium stores, then analyzed by flow cytometry (Becton-Dickinson: East Rutherford, NJ, USA). Fluo-3/AM was excited at the $488 \mathrm{~nm}$ line of an argon laser and the fluorescence intensity was measured at an emission wavelength $530 \mathrm{~nm}$. The determination of CRT translocation onto cell membrane was performed similarly, except that HT-29 cells were stained with FITC as described in 4.7. Isotype-matched IgG antibodies were used as a control.

\subsection{Detection of HMGB1 Release}

HT-29 cells were plated in 6-well plates $\left(1 \times 10^{6}\right.$ cells $\left./ \mathrm{mL}\right)$ with $2 \mathrm{~mL}$ medium. The medium was changed $24 \mathrm{~h}$ later and treatment was added into the cells. Supernatants were collected by centrifugation and were frozen immediately. Quantification of HMGB1 in the supernatants was assessed by enzyme-linked immunosorbent assay according to the manufacturer's instructions $\left(Y=0.00706 X+0.00467, R^{2}=0.9935\right)$.

\subsection{Statistical Analysis}

All experiments were performed in triplicate and results were expressed as means \pm standard deviation (SD). Statistical analyses were carried out with SPSS 19.0 (SPSS Inc.: Chicago, IL, USA). One-way 
ANOVA followed by Duncan's post hoc test were used. Results were considered statistically significant when $p<0.05$ and highly significant when $p<0.01$.

\section{Conclusions}

In this study, we extracted X12-PG from the L.paracasei subp. paracasei X12 using a modified TCA method. X12-PG contained the four representative amino acids Asp, Glu, Ala and Lys, and displayed similar lysozyme sensitivity, UV-visible scanning spectrum and molecular weight as the peptidoglycan standard, all of which indicated that X12-PG was essentially a peptidoglycan. X12-PG can also induce ICD in HT-29 cells, with the hallmarks of CRT exposure and through the ER-targeted as well as $\mathrm{Ca}^{2+}$-signaling pathway. To our knowledge, few studies have reported the immunogenic induction mediated by probiotics. Our studies further enlighten the future application of probiotics as a dietary anticancer therapy.

\section{Acknowledgments}

This work was supported by the project "Harbin outstanding academic leaders" (NO. 2014RFXXJ099), "Harbin Institute of Technology Project" (NO. AUGA9833213611) and "Science and Technology Program of Heilongjiang Provincial Department" (NO. 12541763). We thank Yongping Bao (University of East Anglia, UK) for the critical reading of this manuscript.

\section{Author Contributions}

Yu-Juan Shan and Jing-Yu Chen conceived and designed the studies; Jing-Yu Chen and Bao-Long Li performed the experiments; Jin-Na Zhang and Min Yu contributed reagents and analysis tools; Yu-Juan Shan and Lan-Wei Zhang provided overall supervision and guidance; Pei-Jun Tian and Bao-Long Li analyzed data, discussed the results and wrote the paper.

\section{Conflicts of Interest}

The authors declare no conflict of interest.

\section{References}

1. Siegel, R.L.; Miller, K.D.; Jemal, A. Cancer statistics, 2015. CA: Cancer J. Clin. 2015, 65, 5-29.

2. Kasdagly, M.; Radhakrishnan, S.; Reddivari, L.; Veeramachaneni, D.R.; Vanamala, J. Colon carcinogenesis: Influence of western diet-induced obesity and targeting stem cells using dietary bioactive compounds. Nutrition 2014, 30, 1242-1256.

3. Terzić, J.; Grivennikov, S.; Karin, E.; Karin, M. Inflammation and colon cancer. Gastroenterology 2010, 138, 2101-2114.

4. McCoy, W.; Mason, J.M., 3rd. Enterococcal endocarditis associated with carcinoma of the sigmoid; report of a case. J. Med. Assoc. State Ala. 1951, 21, 162-166.

5. Arthur, J.C.; Perez-Chanona, E.; Mühlbauer, M.; Tomkovich, S.; Uronis, J.M.; Fan, T.-J.; Campbell, B.J.; Abujamel, T.; Dogan, B.; Rogers, A.B. Intestinal inflammation targets cancer-inducing activity of the microbiota. Science 2012, 338, 120-123. 
6. Keku, T.O.; Dulal, S.; Deveaux, A.; Jovov, B.; Han, X. The gastrointestinal microbiota and colorectal cancer. Am. J. Physiol. Gastrointest. Liver Physiol. 2014, 308, G351-G363.

7. Wang, T.; Cai, G.; Qiu, Y.; Fei, N.; Zhang, M.; Pang, X.; Jia, W.; Cai, S.; Zhao, L. Structural segregation of gut microbiota between colorectal cancer patients and healthy volunteers. ISME J. 2012, 6, 320-329.

8. Klaenhammer, T.R.; Kleerebezem, M.; Kopp, M.V.; Rescigno, M. The impact of probiotics and prebiotics on the immune system. Nat. Rev. Immunol. 2012, 12, 728-734.

9. Gourbeyre, P.; Denery, S.; Bodinier, M. Probiotics, prebiotics, and synbiotics: Impact on the gut immune system and allergic reactions. J. Leukoc. Biol. 2011, 89, 685-695.

10. Nova, E.; Abad, C.; Gómez-Martínez, S.; Pozo-Rubio, T.; Marcos, A. Probiotics and Prebiotics in Immune System Protection. In Probiotics and Prebiotics in Food, Nutrition and Health; Otles, S., Ed.; CRC Press: Boca Raton, FL, USA, 2013; Volume 13, p. 269.

11. Urbanska, A.M.; Bhathena, J.; Martoni, C.; Prakash, S. Estimation of the potential antitumor activity of microencapsulated Lactobacillus acidophilus yogurt formulation in the attenuation of tumorigenesis in Apc (Min/+) mice. Dig. Dis. Sci. 2009, 54, 264-273.

12. Ishikawa, H.; Akedo, I.; Otani, T.; Suzuki, T.; Nakamura, T.; Takeyama, I.; Ishiguro, S.; Miyaoka, E.; Sobue, T.; Kakizoe, T. Randomized trial of dietary fiber and Lactobacillus casei administration for prevention of colorectal tumors. Int. J. Cancer 2005, 116, 762-767.

13. Liu, Z.; Qin, H.; Yang, Z.; Xia, Y.; Liu, W.; Yang, J.; Jiang, Y.; Zhang, H.; Wang, Y.; Zheng, Q. Randomised clinical trial: The effects of perioperative probiotic treatment on barrier function and post-Operative infectious complications in colorectal cancer surgery-A double-blind study. Aliment. Pharm. Ther. 2011, 33, 50-63.

14. Kumar, M.; Nagpal, R.; Verma, V.; Kumar, A.; Kaur, N.; Hemalatha, R.; Gautam, S.K.; Singh, B. Probiotic metabolites as epigenetic targets in the prevention of colon cancer. Nutr. Rev. 2013, 71, 23-34.

15. Amrouche, T.; Boutin, Y.; Prioult, G.; Fliss, I. Effects of bifidobacterial cytoplasm, cell wall and exopolysaccharide on mouse lymphocyte proliferation and cytokine production. Int. Dairy J. 2006, $16,70-80$.

16. Clinical Outcomes of Surgical Therapy Study Group. A comparison of laparoscopically assisted and open colectomy for colon cancer. N. Engl. J. Med. 2004, 350, 2050-2059.

17. Wiwanitkit, V. Plateletcrit, mean platelet volume, platelet distribution width: Its expected values and correlation with parallel red blood cell parameters. Clin. Appl. Thromb. Hemost. 2004, 10, $175-178$.

18. Aliustaoglu, M.; Bilici, A.; Seker, M.; Dane, F.; Gocun, M.; Konya, V.; Ustaalioglu, B.B.; Gumus, M. The association of pre-treatment peripheral blood markers with survival in patients with pancreatic cancer. Hepato-Gastroenterology 2010, 57, 640-645.

19. Kahouli, I.; Tomaro-Duchesneau, C.; Prakash, S. Probiotics in colorectal cancer (CRC) with emphasis on mechanisms of action and current perspectives. J. Med. Microbiol. 2013, 62, 1107-1123.

20. Sorbara, M.T.; Philpott, D.J. Peptidoglycan: A critical activator of the mammalian immune system during infection and homeostasis. Immunol. Rev. 2011, 243, 40-60.

21. Fichera, G.A.; Giese, G. Non-immunologically-mediated cytotoxicity of Lactobacillus casei and its derivative peptidoglycan against tumor cell lines. Cancer Lett. 1994, 85, 93-103. 
22. Wang, S.-M.; Zhang, L.-W.; Fan, R.-B.; Han, X.; Yi, H.-X.; Zhang, L.-L.; Xue, C.-H.; Li, H.-B.; Zhang, Y.-H.; Shigwedha, N. Induction of HT-29 cells apoptosis by lactobacilli isolated from fermented products. Res. Microbiol. 2014, 165, 202-214.

23. Tesniere, A.; Panaretakis, T.; Kepp, O.; Apetoh, L.; Ghiringhelli, F.; Zitvogel, L.; Kroemer, G. Molecular characteristics of immunogenic cancer cell death. Cell Death Differ. 2007, 15, 3-12.

24. Obeid, M.; Tesniere, A.; Ghiringhelli, F.; Fimia, G.M.; Apetoh, L.; Perfettini, J.-L.; Castedo, M.; Mignot, G.; Panaretakis, T.; Casares, N. Calreticulin exposure dictates the immunogenicity of cancer cell death. Nat. Med. 2007, 13, 54-61.

25. Ardelt, P.U.; Kneitz, B.; Adam, P.; Reiss, C.; Kocot, A.; Fensterle, J.; Chen, L.; Pasqualini, R.; Arap, W.; Gerharz, E.W. Reactive antibodies against bacillus Calmette-Guerin heat-shock protein-65 potentially predict the outcome of immunotherapy for high-grade transitional cell carcinoma of the bladder. Cancer 2010, 116, 600-609.

26. Apetoh, L.; Ghiringhelli, F.; Tesniere, A.; Obeid, M.; Ortiz, C.; Criollo, A.; Mignot, G.; Maiuri, M.C.; Ullrich, E.; Saulnier, P. Toll-like receptor 4-dependent contribution of the immune system to anticancer chemotherapy and radiotherapy. Nat. Med. 2007, 13, 1050-1059.

27. Elliott, M.R.; Chekeni, F.B.; Trampont, P.C.; Lazarowski, E.R.; Kadl, A.; Walk, S.F.; Park, D.; Woodson, R.I.; Ostankovich, M.; Sharma, P. Nucleotides released by apoptotic cells act as a find-me signal to promote phagocytic clearance. Nature 2009, 461, 282-286.

28. Menger, L.; Vacchelli, E.; Adjemian, S.; Martins, I.; Ma, Y.; Shen, S.; Yamazaki, T.; Sukkurwala, A.Q.; Michaud, M.; Mignot, G. Cardiac glycosides exert anticancer effects by inducing immunogenic cell death. Sci. Transl. Med. 2012, 4, 143 ra99.

29. Kroemer, G.; Galluzzi, L.; Kepp, O.; Zitvogel, L. Immunogenic cell death in cancer therapy. Annu. Rev. Immunol. 2013, 31, 51-72.

30. Schumann, P. 5 Peptidoglycan Structure. Methods Microbiol. 2011, 38, 101-129.

31. Ko, A.; Kanehisa, A.; Martins, I.; Senovilla, L.; Chargari, C.; Dugue, D.; Marino, G.; Kepp, O.; Michaud, M.; Perfettini, J. Autophagy inhibition radiosensitizes in vitro, yet reduces radioresponses in vivo due to deficient immunogenic signalling. Cell Death Differ. 2014, 21, 92-99.

32. Sekine, K.; Toida, T.; Saito, M.; Kuboyama, M.; Kawashima, T.; Hashimoto, Y. A new morphologically characterized cell wall preparation (whole peptidoglycan) from Bifidobacterium infantis with a higher efficacy on the regression of an established tumor in mice. Cancer Res. 1985, $45,1300-1307$.

33. Jun, Y.; Hong, H. Isolation and purification of whole peptidoglycan from Bifidobacterium Bifidum. Chin. J. Microecol. 1997, 5, 12-15.

34. Butler, C.A.; Hoffman, P.S. Characterization of a major 31-kilodalton peptidoglycan-bound protein of Legionella pneumophila. J. Bacteriol. 1990, 172, 2401-2407.

35. Schleifer, K.H.; Kandler, O. Peptidoglycan types of bacterial cell walls and their taxonomic implications. Bacteriol. Rev. 1972, 36, 407-477.

36. Vacchelli, E.; Aranda, F.; Eggermont, A.; Galon, J.; Sautès-Fridman, C.; Cremer, I.; Zitvogel, L.; Kroemer, G.; Galluzzi, L. Trial watch: Chemotherapy with immunogenic cell death inducers. Oncoimmunology 2014, 3, e27878. 
37. Prisciandaro, L.D.; Geier, M.S.; Butler, R.N.; Cummins, A.G.; Howarth, G.S. Evidence supporting the use of probiotics for the prevention and treatment of chemotherapy-induced intestinal mucositis. Crit. Rev. Food Sci. Nutr. 2011, 51, 239-247.

38. Russo, F.; Orlando, A.; Linsalata, M.; Cavallini, A.; Messa, C. Effects of Lactobacillus rhamnosus GG on the cell growth and polyamine metabolism in HGC-27 human gastric cancer cells. Nutr. Cancer 2007, 59, 106-114.

39. Thirabunyanon, M.; Boonprasom, P.; Niamsup, P. Probiotic potential of lactic acid bacteria isolated from fermented dairy milks on antiproliferation of colon cancer cells. Biotechnol. Lett. 2009, 31, 571-576.

40. Choi, S.; Kim, Y.; Han, K.; You, S.; Oh, S.; Kim, S. Effects of Lactobacillus strains on cancer cell proliferation and oxidative stress in vitro. Lett. Appl. Microbiol. 2006, 42, 452-458.

41. Zitvogel, L.; Galluzzi, L.; Smyth, M.J.; Kroemer, G. Mechanism of action of conventional and targeted anticancer therapies: Reinstating immunosurveillance. Immunity 2013, 39, 74-88.

42. Görlach, A.; Klappa, P.; Kietzmann, D.T. The endoplasmic reticulum: Folding, calcium homeostasis, signaling, and redox control. Antioxid. Redox Sign. 2006, 8, 139-1418.

43. Tufi, R.; Panaretakis, T.; Bianchi, K.; Criollo, A.; Fazi, B.; di Sano, F.; Tesniere, A.; Kepp, O.; Paterlini-Brechot, P.; Zitvogel, L. Reduction of endoplasmic reticulum $\mathrm{Ca}^{2+}$; levels favors plasma membrane surface exposure of calreticulin. Cell Death Differ. 2008, 15, 274-282.

44. Dubois, M.; Gilles, K.A.; Hamilton, J.K.; Rebers, P.A.; Smith, F. Colorimetric method for determination of sugars and related substances. Anal. Chem. 1956, 28, 350-356.

45. Kumar, S.; Ciraolo, G.; Hinge, A.; Filippi, M.-D. An efficient and reproducible process for transmission electron microscopy (TEM) of rare cell populations. J. Immunol. Methods 2014, 404, 87-90.

46. Borhani Dizaji, N.; Basseri, H.R.; Naddaf, S.R.; Heidari, M. Molecular characterization of calreticulin from Anopheles stephensi midgut cells and functional assay of the recombinant calreticulin with Plasmodium berghei ookinetes. Gene 2014, 550, 245-252.

47. Omann, G.M.; Harter, J.M. Pertussis toxin effects on chemoattractant-induced response heterogeneity in human PMNs utilizing fluo-3 and flow cytometry. Cytometry 1991, 12, 252-259.

(C) 2015 by the authors; licensee MDPI, Basel, Switzerland. This article is an open access article distributed under the terms and conditions of the Creative Commons Attribution license (http://creativecommons.org/licenses/by/4.0/). 